\title{
MANDEVILLE: LA CULTURA DEL SENTIMIENTO RELIGIOSO
}

\author{
POR \\ JULIO SEOANE PINILLA ${ }^{1}$ \\ Universidad de Alcalá
}

\begin{abstract}
RESUMEN
Mandeville es un autor que con claridad apostó por la tolerancia religiosa y por una religión de Estado con la que el «hábil político» era capaz de lograr la cohesión social y el progreso económico. Mi trabajo muestra esta evidencia como punto de partida pero quiere presentar un hecho curioso: una vez que el trabajo de organización político y social se ha realizado con materiales meramente humanos (no religiosos), Mandeville considera que es necesario plantearse preguntas de cariz religioso que tratan a Dios como un amigo que nos da esperanza para poder vivir en un mundo de escala humana.
\end{abstract}

PALABRAS CLAVE: Mandeville; teología política; tolerancia religiosa; llustración y Religión.

\section{MANDEVILLE: RELIGION FROM THE RELIGIOUS SENTIMENT}

\begin{abstract}
Mandeville is an author who clearly bet on religious tolerance and a state religion with which the clever politician was able to achieve social cohesion and economic progress. My work shows this evidence as a starting point but pretends to present that once the work of political and social organization has been made with merely human (non-religious) material Mandeville considers that it is necessary to ask questions of a religious nature that treat God as a Friend who gives us the needed hope to live in a world of just a human mesure.
\end{abstract}

KEY WORDS: Mandeville; Political theology; Religious toleration; Enlightenment and Religion.

Cómo CITAR ESTE ARTículo / CITATION: Seoane Pinilla, J. 2018. «Mandeville: la cultura del sentimiento religioso». Hispania Sacra 70, 141: 115-123. https://doi.org/10.3989/hs.2018.011

\author{
Recibido/Received 09-05-2017 \\ Aceptado/Accepted $\quad$ 09-06-2017
}

\section{INTRODUCCIÓN}

En este trabajo, me propongo releer el mundo de Bernard de Mandeville para tratar de presentar su acercamiento a la religión. ${ }^{2}$ No es este un aspecto descuidado de la obra de Mandeville a quien ha sido habitual tomarle como un

${ }^{1}$ julio.seoane@uah.es / ORCID iD: http://orcid.org/0000-00017290-0129

2 Citaré sus obras de la siguiente manera: B. Mandeville, The Fable of the Bees or Private Vices, Publick Benefits, 2 vols. (edición de F. B. Kaye de 1924), Indianapolis: Liberty Fund, 1988 (citaré como The Fable y entre paréntesis referiré también el número de página de la edición española: B. Mandeville, La fábula de las abejas, México: F. C. E., 1982). B. Mandeville, An Inquiry into the origin of Honour and the Usefulness of Christianity in War, Londres, 1732 (citaré como Honour). B. Mandeville, Free Thoughts on Religion, the Church, and National Happiness, Londres, 1720 (citaré como Free Thoughts). adalid de la tolerancia religiosa al mismo tiempo que como un representante del modo de apostar, de un modo tremendamente pragmático, por lo que podríamos llamar la «religión civil», esto es, por comprender la religión como un mero mecanismo de control y organización social que ha de estar supeditado al poder político. Ambas asunciones son ciertas, pero estoy convencido de que en Mandeville se sostiene siempre un poso de preocupación teológica que, una vez que se ha puesto en claro la función social de la religión la cual tiene poco que ver con la fe, reclama el derecho del sentimiento natural religioso que anida en cada ser humano. Un sentimiento del que nada se puede decir puesto que se establece en la creencia de un mundo «más allá» que durante toda la Fábula de las abejas se ha mostrado como algo si no inexistente, sí prohibido al lenguaje común de los mortales. Por decirlo brevemente, mi tesis es que una vez que se ha puesto en claro que la 
religión es simplemente una herramienta de coordinación y administración social, surge la evidencia de que algo debemos decir de nuestra relación con Dios (aunque es obvio que lo que digamos excede en mucho el mundo del que podemos hablar con razón y claridad). En este último sentido el sentimiento religioso tiene que ver con el relato, con la reconstrucción que hacemos de nuestras esperanzas; quizás no se refiere tanto a Dios, cuanto a una preocupación por con Él, dar coherencia al mundo en el que vivimos con útiles meramente humanos.

Para llevar a cabo mi trabajo en primer lugar (1) daré una panorámica general del pensamiento de Mandeville y mostraré como su trabajo reposa en el desenmascaramiento de todo lenguaje que exceda los límites de lo meramente humano. Posteriormente (2) daré cuenta de cual es su comprensión de la fe y de la religión para pasar (3) a mostrar a la religión instituida en iglesia como un órgano de gestión social. Función que puede ser desarrollada por cualquier religión siempre y cuando los frutos que dé sean los del progreso (de aquí la apuesta por la libertad religiosa). A continuación (4) mostraré como una vez que ya está fundado el mundo de lo humano y delimitado aquello de lo que podemos hablar con cierta cordura y sensatez, Mandeville comienza una disquisición teológica que en principio no tiene ningún sentido pues ya se ha puesto en claro que Dios no es nada sino nuestro deseo de orden y organización social. A través de esta discusión intentaré presentar la postura de Mandeville ante la religión de un modo novedoso y original que la relaciona no tanto con Dios cuanto con el relato en el que depositamos nuestras esperanzas, relato que actuará como fundamento (quizás contingente, quizás histórico) de nuestra vida social y personal.

\section{UNA RÁPIDA PRESENTACIÓN DEL PENSAMIENTO DE MANDEVILLE}

Aunque ya había traducido alguna fábula de La Fontaine, Bernard Mandeville se dio a conocer cuando en 1705 publicó La colmena refunfuñona, o los bribones se convierten en honrados, un poema que se vendió en hojas sueltas con bastante éxito lo cual le llevaría a ampliarlo, ya en 1714, con algunas explicaciones añadidas bajo el título de La fábula de las abejas que sería la obra por la que cobró fama. Se repitió el éxito en ventas y en 1723 se volvió a reeditar con dos ensayos más que no decrecieron su éxito; posteriormente incorporó una carta de defensa y en las sucesivas reelaboraciones el inicial poema se fue convirtiendo en un palimpsesto que no obedecía a un diseño prefijado, sino que iba incorporando distintas defensas y aplicaciones que Mandeville hacía de su obra a la luz de las críticas y comentarios. En 1729, casi al final de la vida de Mandeville, se publica una nueva edición que además de los textos añadidos anteriormente presenta una segunda parte de La fábula en la que Mandeville incorpora algunos cambios y matizaciones a su obra inicial. Ello termina determinando el carácter de palimpsesto, de libro ni pretencioso ni sistemático (Wilde 1898) de La fábula y algunos autores últimamente han hecho hincapié en la diferencia entre ambas partes planteando que son libros muy distintos. ${ }^{3}$ Hay que decir que hay diferencias

3 V. g. Tolonen 2013. No quiero dejar la ocasión de señalar que $L a$ fábula se convirtió en un fenómeno editorial muy comentado; en «los entre ambas partes; sin ir más lejos los estilos elegidos son distintos (una fábula satírica en la primera parte y un diálogo en la segunda), pero en esencia se quiere decir lo mismo por más que cada vez se intente decir de un modo más afinado. ${ }^{4}$ Para añadir algo más de confusión, justo el año de su muerte, en 1732, se publicó The Origin of Honour and the Usefulness of Christianity in War. Este texto es una segunda parte de la segunda parte de La fábula: son los mismos personajes dialogando con un estilo parecido con lo que no es equivocado considerar a esta obra como una tercera parte de La fábula lo cual incrementaría su calidad de palimpsesto.

¿A qué era debido el éxito de La fábula de las abejas? "Vicios privados, virtudes públicas» es la paradoja que articula La fábula y contra la que se enfrentan todos sus críticos. En la mayoría de las ocasiones no fue sino lo único que se leyó de la misma. La idea de Mandeville es sencilla: las sociedades comerciales de principios del XVIII se mueven por el interés, por el deseo de satisfacer los deseos privados. Antes que cuestiones de benevolencia o de amor al prójimo son intereses personales los que llevan al comerciante a progresar, al banquero a crecer o a las naciones a generar riqueza. La idea de La fábula es que una sociedad de gente buena, amable y amante de los demás, pudiera ser posible, pero no podría llegar al nivel de progreso y riqueza que el mundo que se tomaba como moderno tenía. Como luego afirmará con crudeza A. Smith, no es por amor al prójimo o por benevolencia que sé que el carnicero me venderá la carne que debo poner luego en la mesa. La característica de La fábula es que de un modo minucioso desarticula todos los comportamientos que habitualmente eran calificados de virtuosos y pone a las claras que tienen una finalidad egoísta. Egoísta en el sentido de que si hacen el bien a los demás no es por gusto de hacer el bien, sino por deseo de verse o ensalzado ante los ojos de los demás o de incrementar el propio patrimonio (para con ello satisfacer los deseos, los vicios, privados). ¿Ello es así siempre, en todas las ocasiones? Mandeville meticulosamente va analizando cada aspecto de la vida en la moderna y rica sociedad comercial y contesta que sí, demostrando que cualquier llamada a la razón o a la benevolencia es una hipocresía que intenta vestir con bellos ropajes lo que no es sino el impulso más básico de la humanidad: la satisfacción inmediata de los deseos.

Aquello que primeramente llamó la atención de sus contemporáneos fue la crudeza con que Mandeville planteó la divergencia entre el modo rigorista de entender la virtud (en el cual verdaderamente se comprendía la sociedad de su tiempo) y la evidente vida poco rigorista que estaba estableciéndose con la sociedad comercial de inicios del

cinco años siguientes a 1724 algo más de diez libros se publicaron atacando a La fábula de las abejas por filósofos y hombres de iglesia tan eminente como William Law, John Denis, Francis Hutcheson, Archivald Campbell e Isaac Watts. Además la obra fue sujeto continuo de ataques en sermones, cartas en la prensa y en 1728 de nuevo fue presentada ante el Gran Jurado de Middlesex» (Nokes 1987: 145).

4 Malcom Jack ya en el Prefacio de su importante trabajo sobre Mandeville (Jack 1987), avanza su convencimiento de que Mandeville una y otra vez, desde distintos ámbitos de análisis repite lo mismo: no somos sino animales que pretenden sobrevivir y todo lo que inventamos tiene tal propósito. Hay un sustrato antropológico de corte biologicista que subyace a todas las diferentes intervenciones del médico que realmente era Mandeville. 
XVIII. Aquí es donde tiene sentido la paradoja: el mundo moderno no puede tener a su base (por mucho que asi lo anuncie en el cuadro de sus virtudes "oficiales») la despreocupación por los propios intereses ni el hecho de que la satisfacción de estos es prioritaria a la benevolencia.

Realmente la paradoja «vicios privados, virtudes públicas" se resuelve cuando se intercala un verbo entre ambos términos de la oración. Mandeville explica bien pronto en La fábula lo que quiere decir, a saber, que «los vicios privados convenientemente organizados pueden convertirse en virtudes públicas» y sin mucha dilación pasa a explicar cómo los vicios privados, (a) convenientemente organizados y manejados a través del orgullo y la vanidad por (b) un hábil político, devienen bienes públicos. Estos son los conceptos principales de nuestro autor y los que a continuación toca presentar siquiera con alguna pequeña demora.

(a): El hábil político. Esta fue la primera crítica que le dirigió Butler: si sólo se actúa de modo egoísta y pasional es difícil que un egoísta actúe de modo instrumental pues no tendrá en la mente otra idea sino la satisfacción de una pasión inmediata y no le valdrá ningún plan para mejorar la satisfacción total. De tal manera si todo se redujera al primer deseo de autopreservación, al egoísmo que busca satisfacer las necesidades primeras, habríamos perecido en un mundo de lobos en el cual jamás hubiera sido posible establecer sociedad. Esto era algo tan evidente para Mandeville que debió rasgarse las vestiduras ante la primera crítica a su Fábula: apenas la habían hojeado pues ciertamente en su obra no se tarda mucho en establecer el origen de la sociabilidad humana en el momento en que el egoísmo se dio cuenta de que satisfaría mejor sus intereses si era capaz de demorar la satisfacción inicial y sustituirla por una mucho mayor, la que proporcionaba la vanidad. El mecanismo por el cual el orgullo, la adulación y la vanidad pueden conseguir esta hábil «doma» lo pone en marcha el «hábil político».

Mandeville habla del "hábil político» aunque generalmente no pone ningún ejemplo que al personificarlo en alguien conocido nos pudiera orientar sobre lo que quiere decir. Más bien aparece esta idea para subrayar la importancia de la organización política (que lo es económica, social y religiosa) a la hora de socializar nuestros deseos e intereses. ${ }^{5}$ La habilidad del político reside en su capacidad para "engañar» a sus súbditos para que encuentren placer personal en una serie de deseos cuya satisfacción genera riqueza social. No es que no sean sus propios y particulares deseos, sino que la habilidad política ha sido capaz de inculcar una serie de "deseos» cuyo consumo, por decirlo así, supone más placer que el consumo de los primeros y más primitivos deseos que pudiéramos haber tenido. Siempre actuaremos de modo egoísta, tan sólo pensando en nuestra satisfacción personal, pero nuestros deseos están

5 De hecho el «hábil político» en la segunda parte de La fábula se transforma en el lento devenir histórico desde distintas acciones políticas que de un modo no siempre calculado llevan hasta nuestro presente. Ciertamente ello ya era así en sus primeras intervenciones en el Female Tatler; debemos tomar la noción de «hábil político» como una metáfora para significar un conjunto no fácilmente discernible de procesos políticos, sociales e históricos que de manera no calculada ha llevado hasta el presente. Realmente sería imposible imaginar una sola persona tan inteligente y hábil (y que en lugar de pensar en sí, pensara en la sociabilidad general) como un concreto «hábil político». puestos ahí merced a la argucia política y su satisfacción por más que sea particular termina generando riqueza y no discusión. Podemos imaginar que el hábil político fomenta la creencia en que el espíritu patriótico es muy encomiable y que tal patriotismo se expresa claramente, por ejemplo, consumiendo productos nacionales. Quizás en un primer momento gustemos más de las fresas holandesas que de las nacionales, pero ese gusto palidece ante el placer que sentimos cuando los demás nos señalan admirativamente por consumir fresas patrias aun cuando sean más caras. Para Mandeville nadie hay que no se complazca con la adulación ajena y esta puede venir en forma de reconocimiento social, cultural o político. El orgullo y la vanidad son las dos herramientas que el hábil político ha de saber usar pues es la única manera de hacernos sociables no de un modo obligado sino deseado: que mis vecinos me tengan como un patriota tan generoso que soy capaz de pagar algo más por un producto nacional que por otro importado es algo que me enorgullece y me da mucho más placer que el que me daría poder comer más cantidad de fresas caso de que consumiera las más económicas, las foráneas. Creo que no es menester dar más vueltas a este asunto y el ejemplo puede ampliarse, como lo hace Mandeville, hasta el duelo o el valor en la batalla; en ambos casos el miedo a la muerte queda oscurecido por el gozo que me proporcionan los encomios hacia mi honor o mi patriotismo (gozo imaginado, es cierto, pero no menos placentero). Es de esta manera que se generan las morales y cualquier tipo de organización social. No hay una razón para ser sociales, sólo un gusto o una satisfacción egoísta que se genera por el orgullo y la vanidad. ${ }^{6}$

(b): El honor, el orgullo, el apego a sí. La mejor manera de controlar nuestros deseos egoístas es crear un placer mayor que el que se satisfaría con tales deseos; tal placer es el que da el orgullo y la vanidad (el placer imaginado de la estima ante los demás es más poderoso que los placeres sensoriales que advienen de la complacencia inmediata esto es algo que ya había advertido La Rochefoucauld-). El «hábil político» es el que consigue organizar el mundo social; con las herramientas del orgullo y la vanidad construye los mecanismos del honor, las diferentes situaciones, acciones y comportamientos que estamos dispuestos a considerar como estimables. Eso y no otra cosa es lo que hace el hábil político: no moralizar sino combinar pasiones mediante la alabanza pública para que estas se puedan coordinar fructíferamente en una vida social.

Es así como nuestras leyes, nuestras morales, nuestros procesos organizativos y de consumo, etc., quedan reguladas a través no de la virtud natural (¿qué es eso? clama Mandeville contra Shaftesbury de modo continuo), sino desde mecanismos creados unas veces ad hoc, otras veces a través de una serie de casualidades o de

6 El egoísmo se ha transmutado y termina siendo un poderoso instrumento de educación y sociabilidad: creamos órdenes morales que en principio no satisfacen nuestro inicial amor a nosotros mismos (el gusto que sentimos cuando no tenemos dolor y estamos tranquilos), pero que por la argucia del hábil político realmente nos complacen mucho más que ese nuestro primer deseo natural de auto-preservación. Complacerse incluso con la posibilidad de perder la vida, o con el dolor de una mala herida, es algo que la habilidad del político ha logrado inculcarnos y el mejor ejemplo del modo como nos socializamos. 
confluencias con otros mecanismos, con los que se articula nuestra natural propensión al orgullo y la vanidad. De este modo no somos primeramente sociables, sino que somos sociables porque somos primeramente egoístas ${ }^{7}$ : en las sociedades comerciales la afirmación de nuestros deseos, de nuestros vicios, se transforma en un mundo sociable, de bienes públicos. Al afirmar el orgullo y la vanidad como sentimientos innatos a nuestra naturaleza Mandeville es capaz de construir un mundo social sin ir más allá de la preocupación por complacerse a sí mismo; preocupación que supone al mismo tiempo el cuidado para que los demás estén complacidos con mis actuaciones.

En la segunda parte de La fábula Mandeville se dio cuenta de que el orgullo y la vanidad se le quedaban cortos para dar cuenta de toda nuestra vida. Que el mundo moral que se construye desde el honor no es fácil sostenerlo si sólo contamos con la vanidad y el orgullo. Además, algunos críticos - Butler y Hutcheson entre ellos- le habían afrontado que si todo partiera del egoísmo, no cabría entender el amor natural que una madre siente hacia su hijo, un amor que se demostraba según sus críticos, incluso en casos donde no había espectadores. No era este el único caso donde pareciera que actuamos movidos por alguna virtud natural o por lo menos $-\mathrm{y}$ esto es lo más importante- donde a solas actuáramos de modo virtuoso, y el mismo Mandeville se dio cuenta de que el modelaje de las pasiones ha de suponer una pasión primera puesto que «ninguna criatura puede querer lo que no le gusta, es necesario, además, que cada cual tenga por su propio ser mayor simpatía y afección que las que tienen por los demás. Opino, pidiendo perdón por la novedad, que si esta afección no fuera permanente, el amor que tienen todas las criaturas a sí mismas no podría ser tan inalterable como lo vemos» (The Fable, parte II, 129 [438-439]).

Pues bien, en el Diálogo Segundo de la segunda parte de La fábula Mandeville distingue entre el amor a sí mismo (self-love) y el apego a sí (self-liking) y considera que nos componemos con ambos términos, pero que en las sociedades complejas el segundo es el dominante. El apego a sí es el gusto que encontramos por vernos alabados; pero es algo más complejo que la mera vanidad, tal y como Mandeville trata de explicar, porque no es sólo que deseamos ser alabados por, pongamos por caso, nuestra desprendida generosidad pero seguimos siendo internamente unos avaros, sino que nos complace comprendernos como generosos y en ese momento, aun actuando en un inicio hipócritamente llegamos a olvidarnos de nuestra natural tacañería y no podemos sino complacernos cuando nos consideramos a nosotros mismos como generosos ( $y$ actuamos en consecuencia). En un proceso de estilización de sí foucaultiano (y estoy siendo anacrónico con conciencia) el individuo tiende a configurar su identidad del modo en como pretende que los demás le consideren, adquiere cualidades que los otros admiran y en el esfuerzo incluso llega a negar sus primeras inclinaciones (y hasta, llegado el caso, se atreve a desafiar a la muerte

\footnotetext{
7 Mandeville no deja de recordarnos que hay otras pasiones naturales que no son el orgullo o la vanidad; por supuesto, reconoce Mandeville, que tenemos muchas otras pasiones que nos son naturales, somos piadosos y amantes de nuestros hijos y familia, pero esas pasiones no sirven para hacernos sociables.
}

sin necesitar espectadores que aplaudan su actuación). La hipocresía que es la base del mundo del orgullo y la vanidad, se transforma y deja de ser tal hipocresía: el individuo actúa sinceramente. Es bien cierto que lo hace por un deseo de ser bien considerado, pero ello, se podría decir, no sólo «engaña» a los demás, sino también a sí mismo. El análisis se torna ahora más fino y no es extraño que lo recogiera años después Rousseau (tal y como A. Smith advirtió) con su diferenciación entre amour-a-soi y amour-propre. Los vicios privados generan bien público en el momento en que incluso la actuación egoísta se convierte naturalmente en parte de la propia construcción de la identidad. El mero cultivo de la buena educación social que podemos lograr con la vanidad y el orgullo no es suficiente pues en cualquier momento, cuando estuviéramos fuera de la vista de los demás podríamos traicionar toda la sociabilidad. Sólo el apego a sí nos hace sociables en todo momento; incluso cuando no tenemos sociedad ninguna (Monro 1975: 126127 y Peltonen 2003: cap. III).

\section{EL SENTIDO Y MOTIVO DE LA RELIGIÓN}

«La religión en general consiste en un reconocimiento de un poder inmortal que, superior a todo dominio terreno, gobierna el mundo de manera invisible y en un esfuerzo respetuoso para cumplir con aquellos deberes que cada uno comprende que le son requeridos por parte de ese poder inmortal» (Free Thoughts: 1) lo cual es instintivo (The Fable, parte II, 208-210 [497-498]) e innato (Honour 21-22) en tanto en nuestra naturaleza reside un sentimiento religioso natural que nos lleva a creer en la divinidad. El origen de este sentimiento natural es el miedo que la humanidad ha sentido ante el inmenso poder y la distancia que la naturaleza tiene sobre nosotros (Simonazzi 2008: 283285). La única forma de explicar fenómenos naturales o el magnífico orden que se observa en la vida natural y la sola manera de entender que nuestras desgracias tienen algún sentido, que no estamos en manos de un hado inexplicable, es acudiendo a una divinidad que organiza y da sentido incluso a aquello que no podemos comprender. ${ }^{8}$

Pero este inicial sentimiento religioso que cada hombre siente, se va transformando del mismo modo que lo hace la vida social: se organiza bajo un poder religioso y la fe inicial en una divinidad se transforma en creencia en los dogmas y normas de una organización religiosa $-\mathrm{y}$ socialcon sus diferentes valores o virtudes y, sobre todo, con una determinada organización y jerarquía. En este punto el hábil político de La fábula se convierte, bajo el análisis de Mandeville, en el jefe religioso cuyo modo de actuación (al igual que las pautas de la organización de la creencia) es el mismo que se utiliza en un Estado civil: usando del orgullo, la vanidad y, sobre todo, la hipocresía. La religión, al igual que los gobiernos civiles, se organiza del modo en que los vicios privados constituyen virtudes públicas que coadyuvan

8 «Cleómenes: Cuando te pregunté cómo vino la religión al mundo quise decir qué hay en la naturaleza humana que no sea adquirido y en virtud de lo cual tiene una tendencia a la religión. ¿Qué es, en suma, lo que dispone hacia ella. Horacio: El temor» (The Fable: II, 207 [496]). Más adelante Cleómenes afirma: «La misma palabra religión y el temor a Dios son sinónimos» (The Fable: II, 218 [504]). Sobre el particular se puede ver Simonazzi (2015). 
a la solidez del sistema jerárquico que guarda la religión de que se trate. Es un sistema que logra que los conceptos, metáforas e ideas con las que se cohesiona socialmente el grupo religioso se conviertan en las virtudes que disfrazan los intereses de los jefes religiosos y, no se debe olvidar esto, los del sistema social que con ellos cobra estabilidad.

Las regulaciones, las normas, los artículos de fe, los ritos, etc., todo ello tiene como único fin no tanto alabar a la divinidad que de manera natural apareció en el origen de todo sentimiento religioso, sino establecer un grupo social firme y estable a las órdenes de un jefe religioso que sabe utilizar nuestros intereses y como "hábil político", a través del orgullo, la adulación y el apego a sí connatural a la naturaleza humana, es capaz de dar cohesión a su «secta» (el término es de Mandeville).

En este punto Mandeville está convencido de que todas las religiones son iguales. ${ }^{9}$ Su interés es simplemente constituir un grupo social homogéneo y cohesionado del cual cada individuo pueda extraer algún beneficio (siquiera sea el más pequeño y no menos importante: verse reconocido, sentirse "en casa»). ${ }^{10}$ Como ocurre con los diferentes reinos y gobiernos, surgirán conflictos, disputas y guerras entre las distintas Iglesias no tanto por la defensa de un Dios, por supuesto, cuanto por los beneficios que aparecen tras desplegar la bandera que representa a ese Dios; como, además, la creencia en un Dios siempre raya con el fanatismo (desde luego no con la sosegada racionalidad), los conflictos son más sangrantes y duraderos. Por otro lado, siendo la organización religiosa una organización social como lo puede ser el Estado, por tal motivo, compite con este en la medida en que tiene los mismos objetivos y debe hacerse con el mismo espacio social. Por ello Mandeville considerará que la religión en un Estado comercial moderno ha de quedar controlada por el poder político a fin de evitar el conflicto y la inestabilidad que obstaculizarían el progreso y la riqueza de la nación.

Lo interesante de la propuesta de Mandeville es la paradoja de la que parte el mundo religioso, a saber, que siendo la creencia religiosa un sentimiento natural que persigue una explicación espiritual que nos ayude a dar cuenta del mundo natural que nos supera y no podemos entender, se termina sustanciando en una vida religiosa que se ha de oponer por fuerza a tal inicio espiritual. Se ha de oponer pues nuestra vida es plenamente corporal con lo que las explicaciones espirituales, las cuales suponen renunciar a tal vida, no pueden ser de nuestro mundo. En este punto tan sólo hay que recordar el leif-motiv con el que se compone La fábula: la idea de que la virtud no puede existir en una sociedad compleja en la medida en que la virtud supone la renuncia a los propios deseos, al instinto de auto-preservación; la virtud supone la renuncia a sí mismo por consideración a los demás, supone un mundo

\footnotetext{
9 «La diferencia en los principios del clero no es tan grande como muchos imaginan» (Free Thoughts: 246).

10 El carácter de orden político y social de las iglesias, sin relación con el inicial sentimiento religioso, lo muestra de modo continuo Mandeville sobre todo con la exposición de dos características que en la idea de nuestro autor ( $y$ creo que también en la nuestra propia hoy en día) caracterizan a este tipo de orden: la defensa a ultranza de aquellos que están con ellas (sean virtuosos o no [cfr. Free Thoughts: 170]) y su naturaleza muy dada a la corrupción (A Letter to Dion, Londres, 1732: 64-5).
}

que nos haría santos, pero al precio de alejarnos de la vida que gustamos de vivir en esta realidad en la que de hecho desarrollamos nuestra vida. Una sociedad de virtuosos sería pobre y aunque como Mandeville afirma más de una vez, es evidente que puede haber comportamientos y personas virtuosas y espirituales, estas están tan alejadas de nuestro mundo y son tan perniciosas para el desarrollo de una sociedad próspera, que nos son tremendamente ajenas. Esto es algo connatural a la vida terrena que nos toca vivir y en lo que refiere a la religión no podía ser diferente: la inicial apuesta espiritual, el inicial sentimiento religioso en el momento en que da sus primeros pasos, en el momento en que quiere establecerse en nuestro mundo, se transforma en una realidad que nada tiene que ver con la fe en una divinidad y simplemente es un modo más de organización de la vida social que utiliza los únicos medios que los humanos conocemos.

Este es el punto en el cual Mandeville establece una diferencia clara que camina por toda su obra de manera explícita entre la religión del Evangelio y la de los creyentes y, como se puede imaginar, la fe y su virtud se opone a la organización terrena (con cuerpo y sus necesidades) de los fieles de una iglesia. Asumido este doble nivel, Mandeville, como médico anatomista que es, analiza la religión desde el sentimiento natural de la fe, hasta la creencia, el significado de los ritos, la interpretación de las Escrituras, la relación entre religión y fe y el problema de la religión organizada como iglesia dentro de una sociedad; y tras ello le resulta claro que la religión es un modo de organización política más cuyo hábil director trabaja con uno de los mejores y más efectivos instrumentos para disfrazar los intereses: el temor a Dios y el deseo de una vida más allá de esta. Un elemento que no puede ser dejado de lado por la sociedad civil.

\section{LA RELIGIÓN COMO PROVEEDORA DE ARTIFICIOS DE COHESIÓN SOCIAL}

Es evidente que el hábil político o bien las consecuencias insospechadas del decurso histórico del género humano pueden llevar a cabo su función de organización social sólo desde la aculturación, desde la educación de los hombres en aquellos valores, imágenes y virtudes con las que los vicios privados pueden ser llevados hacia el beneficio público. En este sentido la educación es un elemento fundamental en la obra de Mandeville, pues es a través de ella donde se adquieren los elementos del honor, la vergüenza o la dignidad que hacen que una sociedad sea próspera.

Como se puede imaginar no hay una sola escuela en la que se aprendan virtudes, sino que Mandeville juega con la idea de que las diferentes esferas de la vida se reproducen mediante un juego de valores, virtudes o elementos valorativos que empapan a los participantes en el juego social. Lo interesante del caso es que este empapamiento llega hasta el punto de que en la intimidad, en el momento donde el mundo social desaparece, también el apego a sí hace que la configuración de nuestra propia identidad sea deudora de la educación social. Nos convertimos en personas que viven en sociedad, civilizados en mayor o menor medida, a través de un proceso de aculturación continuo; pues bien el elemento más fuerte de tal proceso 
es la religión. No es el único, por supuesto, pero sí es el que con mayor fuerza ha construido el mundo de las sociedades comerciales y el que se muestra como el más capaz de dar cuenta de la complejidad de las mismas: "la disposición innata al miedo a una causa invisible que se mezcla e interfiere en los asuntos humanos y el deseo de aplacarla es obviamente muy útil a la habilidad del político que quiere controlar el comportamiento humano» (Hundert 2005: 151) y por ello todo lo que busca un político lo encuentra fácilmente en las funciones de una iglesia. ${ }^{11}$

El honor, la virtud y los valores que usamos para que nuestro propio interés pueda convertirse en virtudes públicas, necesitan de un sistema de vigilancia, de recompensa y de una seguridad que excede el "acuerdo» humano. Sería absurdo pensar que el honor de dar la vida por la patria tuviera todo su fundamento en el hecho de que los hombres gustamos o hemos acordado complacernos con tal conducta; es preciso que ello tenga como garantía el brazo divino, el hecho de que un Dios que todo lo ve y que está en todas partes sanciona positivamente nuestra honorable actitud. La muchacha que oye una conversación obscena tras una puerta se ruborizará no tanto porque sepa que la oye alguien, cuanto por el hecho de que sabe que ello es algo que la ha de ruborizar y porque además de su propia conciencia siente sobre sí la tutela divina. No ha de olvidarse que con la noción de apego a sí, Mandeville introduce el poder de la aculturación social hasta la intimidad del individuo y es en este lugar donde Dios acude como ayuda esencial. ${ }^{12}$ En nuestra intimidad es bien cierto que trabajamos con valores que se nos han impuesto y que tomamos como propios, valores que no dejan de sernos incómodos — siquiera oculta o «inconscientemente»-, pero ello es así porque aun en el caso en que pudiéramos escapar de nosotros mismos es evidente que nunca podríamos escapar de los ojos de Dios. ${ }^{13}$ Sin tal tutela Mandeville es consciente de que se perdería la mayor parte de la cohesión social que hace de una sociedad un mundo próspero.

11 «Sería difícil nombrar a un rey o a cualquier otro gran hombre de los tiempos antiguos que hubiera intentado gobernar un pueblo naciente sin pretender tener alguna relación, directa o a través de sus antepasados con un poder invisible» (The Fable: II, 218 [504]). "Y si los políticos han tendido a aliarse con la iglesia, esta, a su vez, no ha sido reluctante a ello» (Hundert 2005: 151 y Free Thoughts: 151).

12 «Pues sin la creencia en otro mundo un hombre no está obligado a ser sincero en este. Sus juramentos no podrán atarle» (The Fable: II, 314 [579]).

13 Mandeville nunca es ingenuo y no cree que podamos escapar al conflicto. Ni con los demás ni con nosotros mismos. No pocas veces obramos como creemos que no debemos obrar y hasta nos sentimos culpables de ello. Los preceptos religiosos son un buen instrumento de control, pero entre los seres humanos no es posible encontrar aquello que nunca falle y sea la panacea de nuestro control personal y social. No debemos olvidar que nuestra misma naturaleza siempre está en contra de todo tipo de control por lo que la sociabilidad (entendida incluso la sociedad que tenemos con nosotros mismos) nunca es sencilla por mucho que tengamos, con la religión, el mejor instrumento de control: «Nada es más fácil que creer: Los hombres pueden ser sinceros en su fe e incluso celosos de la religión que profesan y al mismo tiempo llevar vidas malvadas y actuar muy diferente a su creencia. Aquellos que alegremente sufren persecución por su fe no deberían de ser sospechosos de insinceridad; aunque en todos los tiempos ha habido muchos ejemplos de gente que por su religión ha abandonado su país, sus posesiones, empleos, amigos y relaciones pero nunca pudieron conseguir renunciar a sus propios placeres sensuales» (Free Thoughts: 6-7).
Es importante, realmente importante, que haya una creencia religiosa que nos unifique como partícipes de un mismo modelo social. Es la única manera de que la sociedad pueda devenir compleja y rica y es el fundamento de la decidida opción de Mandeville por un clero que como funcionario público engrase el mecanismo de cohesión social; con su ayuda se elaboran los artificios morales y políticos con los que el hábil político es capaz de conducir nuestros intereses, nuestros vicios, hacia el beneficio público. La religión suministra obediencia por medio de la creación de virtudes que tienen su garantía en el Dios de que se trate y que son utilizadas por el hábil político a fin de promover la prosperidad pública. Por ello debe ser bien considerada por el Estado, debe ser incluso promovida y obligatoria: los pobres y sus hijos han de ser forzados a ir los domingos a la iglesia y deben ser educados en las tradiciones del bien y del mal (también se deben promover las Facultades de Teología).

Eso sí, la división del trabajo que exige una sociedad rica ha de quedar bien clara y el clero "funcionarizado» ha de realizar su trabajo con dedicación y con los límites bien claros: lo suyo es la vida ultraterrena, la que está más allá de nuestra sociedad comercial y en este sentido ha de pastorear almas, no cuerpos ni deseos. En caso contrario Mandeville nos muestra, a través de innumerables análisis históricos y discusiones, como disminuye la prosperidad y riqueza de una nación. Sea porque el conflicto violento aparece, sea porque el gobierno eclesial no es el más adecuado ni propicio para forjar una sociedad comercial y próspera, lo cierto es que la disputa del clero con el poder político por los límites de la organización social y de la policía generan pobreza y atentan contra el progreso. Ha de ser bien evidente quien detenta el gobierno de las almas y quien el de los cuerpos (cfr. Free Thoughts, 241-246).

Llegados a este punto hay que decir que buena parte del sometimiento de las iglesias al hábil político se sustancia en la tolerancia religiosa cuya argumentación (sobre todo en los Free Thoughts) es tanto pragmática como teórica. Desde un punto de vista pragmático la tolerancia entre las diferentes religiones disminuiría los conflictos y permitiría a cada religión tener su espacio en el mundo con lo que el conflicto se convertiría en competencia que, es de suponer, generaría progreso en el orden de la organización religiosa y en el de la civil: cada religión afinaría sus atractivos y suavizaría su coexistencia con un Estado (en el que viven otras religiones). ${ }^{14}$ Desde un punto de vista teórico Mandeville argumenta que el mundo del que habla la religión no es de nuestro negociado y, por ello, ni nuestro conocimiento ni nuestro lenguaje son capaces de llegar a nada concluyente cuando se trata de discusiones religiosas. Estas discusiones en último término remiten a la fe la cual

14 Eso sí, tolerancia con todas las religiones siempre y cuando sus iglesias no se ocupen de los asuntos del Estado, lo cual es una propensión muy natural del clero que ha de ser controlado muy de cerca (Free Thoughts: 21 y The Fable: II, 77-8 [397-398]): "Cuando proclamo la tolerancia con las distintas sectas, quiero referirme sólo a aquellas que tienen al Gobierno como su suprema autoridad en la tierra, tanto en la iglesia como en el Estado y no tienen otra cabeza en el extranjero que puedan llevarles a urdir algo contra nuestra seguridad. Es sobre este punto que sólo los papistas y los non jurors deberían ser excluidos, pero ello ha de ser asunto del Estado sobre el que el clero no tiene nada que decir» (Free Thoughts: 241-242). 
no se puede dirimir con argumentaciones racionales ni con discusiones sosegadas y reflexivas por su misma naturaleza (mucho más allá de las unas y de las otras).

No debemos olvidar dónde ha comenzado todo esto: para Mandeville el hombre es un ser que va a la religión de manera natural. El miedo que le da su propia pequeñez ante la naturaleza que es tan peligrosa como magnífica, es el que le lleva a acudir a un Dios para dar cuenta del orden del universo, para dar razón de las desgracias y de las justicias que no siempre se dan pero siempre se anhelan. La religión parte de nuestro inicial equipamiento biológico y desde ahí construye una fe que excede nuestro anclaje natural; y porque le excede Mandeville piensa que nunca habrá una perfecta demostración en cuestiones religiosas. Este es un lugar donde las argumentaciones, nunca podrán ser enteramente claras (James 1975: 48). Pero nuestra falibilidad en cuestiones de religión, en lo que toca al misterio como Mandeville lo llama, no significa, por supuesto, una renuncia a la razón. La postura de Mandeville no pasa por afirmar que puesto que la religión dice cosas más allá de la razón han de ser creídas sin más (en buena medida sería esta la postura de Bayle), sino que piensa que hay cosas contra la razón y cosas que van más allá de la razón. ${ }^{15}$ Contra la razón es pretender ver a través de un sólido. Más allá de la razón es saber que $2+2=4$, pero que en algunos casos esa suma puede ser igual a $5 .{ }^{16}$ La lección es clara para Mandeville: aunque la razón nada nos puede decir de lo que está más allá, lo cierto es que la razón sí que habla de lo que es contradictorio y en el mundo de los humanos debemos obedecerla. Obedecerla incluso para creer en doctrinas religiosas, para dejar un espacio de norazón. ${ }^{17}$

En este punto se suele recordar que Mandeville, ya en el mismo título de sus Free Thoughts, se declara librepensador y ello en su época es una apuesta clara por la tolerancia y coexistencia de religiones. Pero mientras tradicionalmente

15 Hay que decir que esta es una de las pocas diferencias que se han apuntado entre Bayle y Mandeville. Este último utiliza al primero de manera indiscriminada y en muchos casos sus Free Thoughts son paráfrasis, cuando no mera traducción, del Diccionario histórico-crítico (al respecto cfr. Scribano 1980).

16 «Concluiré este capítulo estableciendo claramente con dos ejemplos sencillos la diferencia que hay entre cosas que están por encima de la razón, y sobrepasan nuestra capacidad, y otras que son contra la razón y contradicen la demostración: cuando se dice que un hombre puede ver a través de un roble de dos pulgadas de espesor, completamente sólido y entero, rehusaré creerlo aun con el testimonio de cien mil testigos creíbles. Pero que Dios me haya revelado que ha creado a un individuo tal y yo inmediatamente lo asumiré y, tan pronto como esté seguro de que la Revelación es completamente divina, lo creeré con tanta seguridad y si es posible con menos escrúpulo a como creo que hay un lugar como Japón» (Free Thoughts: 85) y continúa «Cuando un hombre, una vez que sabe que dos y dos son cuatro y aun afirma que cree que dos y dos en una determinada ocasión son siete, si es sincero es evidente que o no sabe lo que dice o no entiende lo que su creencia significa. Porque aunque un hombre puede creer que una cosa sea verdad aunque no la aprehenda como tal, es imposible que crea lo contrario de lo que el aprehende claramente que es verdadero» (Free Thoughts: 87).

17 «Horacio: [...] ¿Puedes comprender cómo algo ha podido proceder de la nada? Cleómenes: Confieso que no lo comprendo más de lo que puedo comprender la eternidad y la divinidad misma, pero cuando no puedo comprender lo que mi razón me afirma que debe existir necesariamente, no hay para mi axioma o demostración más claros que el hecho de que la falta radica en mi escasa capacidad, en la superficialidad de mi entendimiento» (The Fable: II, 310 [577]). los librepensadores eran deístas, ese no es el caso de Mandeville que más bien considera que los deístas son tremendamente arrogantes en su confianza en la razón. Él se apunta a un teísmo convencido de que la razón ha de callar en asuntos de fe, que debe reconocer sus límites y dejar un espacio (que no debe ser el espacio de la organización social) a las no palabras, al convencimiento sin poder de argumentación segura y firme. ${ }^{18}$ No sólo sobre las cuestiones de fe la razón ha de reconocer su desconocimiento (el núcleo mismo de La fábula, supone que las pasiones con las que nos engañamos son fundamentales para la vida humana), además tal silenciamiento es muy necesario en todos los temas esenciales ligados con la religión: el alma, el misterio, el determinismo o la libertad ${ }^{19}$... Eso sí, la vida humana ha de saber organizar sus silencios: obvios para las cuestiones relativas al alma, rechazables cuando se trata de construir una sociedad próspera. ${ }^{20}$

\section{EL DIOS DE LA FE}

Ha sido común en la exégesis de Mandeville enfatizar el carácter utilitario de Dios y de la religión. En este punto las divergencias acerca del trabajo de Mandeville son muy escasas: es claro que el Estado necesita funcionarios religiosos para garantizar la obediencia a las nuevas normas de la sociedad comercial. Consecuentemente Dios se concibe como una parte del universo cultural (en la línea de la virtud, la dignidad, la caridad, etc.) creado por el interés de cohesión social. Pero a pesar de esto, creo que es relevante considerar que una vez ya se ha establecido de una manera clara el modo de organización social de la sociedad comercial (con base en el interés propio, en los vicios privados), en los diálogos $\mathrm{V}$ y VI de la segunda parte de La fábula se puede encontrar una discusión teológica que parece fuera de lugar, sin sentido en la composición del libro. ¿Por qué hablar de Dios, de su esencia, de la fe en Él, cuando ya es evidente que no se le necesita, cuando se ha hecho evidente que se puede entender el mundo humano sin la referencia a la deidad? La discusión que podemos

18 «Estamos convencidos de que el entendimiento humano es limitado, y con poca reflexión podremos asegurarnos de que la angostura de sus límites es la única causa que nos impide escudriñar nuestro origen por la fuerza de la penetración. La consecuencia de ello es que para alcanzar la verdad de ese origen, que es de suma importancia para nosotros, debemos creer en algo» (The Fable: II, 315 [580]).

19 «El alma es siempre incomprensible y poco podemos decir de ella que no nos haya sido revelado» (The Fable: II, 168 [467]). No sabemos siquiera si existe ni, por supuesto, si existe otra vida. El mismo desconocimiento ocurre con la disputa libertad-determinismo donde parece que lo más racional es la hipótesis maniquea que todos los cristianos - y el propio Mandeville también según él mismo declara- deben rechazar. La conclusión es inevitable: tolerancia.

20 Jack (1975: 35 y ss.) propone la tesis de que en el caso de Mandeville Dios aparece como algo inefable y misterioso, incomprensible y que precisa de obediencia ciega no por un resabio calvinista, sino por un interés por la ética: es la única manera de concentrarnos en lo que de hecho tenemos y podemos dominar. Quizás no podamos dar con la verdadera religión, pero sí podemos saber dónde estamos, con qué comunidad vivimos y aquí la religión vale por su doctrina moral (que no viene de Dios, sino de la religión que la guarda). Pero precisamente porque lo que nos interesa de la religión es su valor de organización social, debemos evitar las disputas y guerras y por ello, de nuevo, tolerancia. (Free Thoughts: 319). 
leer en estos dos diálogos finales es acerca de una cuestión sencilla, a saber, la Providencia: ¿crea y mantiene Dios el evidente orden bajo el cual vivimos? Mucho espacio se dedica a este tema para concluir que la respuesta pasa por el reconocimiento de que lo haga o no, lo cierto es que tal orden existe y a los humanos nos sobra con la evidencia de que de hecho vivimos en él.

Quiero insistir en la localización, el lugar donde aparece este Dios innecesario para el progreso y el orden humano que tras toda La fábula ha quedado organizado con medios meramente humanos. Y quiero proponer que aparece para responder algunas cuestiones sin importancia para tal organización (nuestra vida, realmente se ha propuesto como una vida "toda" social), pero cuestiones que nos hacen sentir inquietud. La más importante de estas cuestiones es: ¿hay un orden en el universo previo al orden que nosotros construimos y conocemos (hay algo más que nosotros mismos y nuestras comprensiones)?

En este momento quisiera mencionar uno de los últimos libros de Simon Critchley (2012), La fe de los infieles, una de cuyas principales tesis es que la llustración forjó nuestro mundo con un discurso que afirmaba evitar a Dios y que era presuntamente secular; pero tal huida de Dios fue ficticia porque bajo los conceptos seculares se ocultaba la creencia religiosa y, en consecuencia, nuestra Política se convirtió en una Política Teológica. Esta situación provoca, como afirma Critchley, enormes distorsiones en nuestro presente (en esencia: hemos estado fundando en la política religiosa nuestras democracias seculares y tal actitud genera una democracia que no es una democracia). Quiero recordar a Critchley porque me parece que desde su propuesta Mandeville adquiere diferente luz y se convierte en un ilustrado consecuente - más que radical - . No olvidemos el lema de Mandeville: vicios privados forjan la riqueza social. Desde este punto su trabajo se ha resuelto sin proponer una mano invisible (o una argucia de la razón) que subyace bajo todo nuestro mundo, no ha planteado tampoco una Naturaleza que nos guía aun sin nosotros saberlo, o una Historia que ordena los intereses particulares sin que los individuos particulares sepan nada de los movimientos históricos (todas estas opciones se han dado en la filosofía moderna y todas son susceptibles de la acusación de Critchley: han continuado una política teológica que nada tenía que ver con sus pretensiones de racionalidad secular). Lo que en la Fábula se plantea cuando Mandeville pregunta por el orden cósmico, a saber, si hay realmente - de modo ajeno a nuestros deseos, a nuestras construcciones morales- un orden que ordena el mundo natural, pudiera ir en la línea de los artificios señalados (la mano invisible, la Historia, etc.), pero en su caso no es una pregunta que se pueda incorporar a la agenda social o cultural, sino que es una pregunta que aparece una vez que la política ya ha sido establecida y fundada de una manera puramente humana (que no requiere de la fe).

La mención de Dios no puede ser más innecesaria, pero Mandeville la dedica un espacio largo y muy detallado. Dios aparece no como una parte integral de nuestro mundo social (que, repito, se construye con un discurso que no precisa de la fe), sino como una parte de nuestra identidad, una pregunta que planteamos cuando tenemos inquietud con/de nosotros mismos. Dios puede ser un ardid, un artificio, un mecanismo que ayuda a la estabilidad política y social, pero además de esto (y después de haber construido nuestro mundo a la humana manera y con humanos útiles), es una respuesta a algunas cuestiones que a veces sobrevuelan sobre nosotros. No son estas cuestiones que un anatomista pueda resolver; si hay Providencia, si esta supone un mundo determinista o donde cabe la libertad, cuál es el valor del misterio, hasta dónde podemos tener confianza en nuestra misma razón, son preguntas que nos inquietan en nuestra humana vida y ante las que Dios nos da confianza para afrontarlas.

La riqueza de la nación (bajo la visión de Mandeville) es toda la garantía que necesitan las nociones sociales y políticas: el mundo humano se forja mediante medios humanos $-\mathrm{y}$ progresa con categorías humanas-; pero cuando todo está ya establecido, la vida humana pide un compañero de viaje que acompañe al ingenio del gobierno. ¿Un compañero? Sí, porque aunque todo funciona correcta y prósperamente por medios meramente humanos, lo cierto es que siempre surge la pregunta de si ello realmente es así y de por qué motivo es así. No es precisa una respuesta para vivir, pero sí algo que nos dé confianza para poder llevar la pregunta sin respuesta a través de nuestra vida. Y sin una Historia fuerte, sin un concepto de Naturaleza que nos conduzca, Mandeville apuesta por una Providencia bien curiosa. Un providencia sobre la que no se puede argüir en público, pero que sí ha de empapar el convencimiento particular.

En este punto me gustaría señalar algo importante: no es el caso que Dios sea relegado al mundo privado de cada hombre, que Él sea una opción de la naturaleza moral particular de los seres humanos; es evidente que las respuestas a la inquietud de la divinidad pueden ser variadas, que no tienen por qué ser iguales, pero ello no supone que tal pregunta deba desaparecer en los recovecos privados de cada quien. De hecho esa inquietud que lleva a hablar de algo que nos excede y para lo que ni tenemos lenguaje ni razón, es parte esencial de la cultura moral que es precisa para vivir con los demás.

Creo que Mandeville pensaba que nos era precisa la esperanza de que la riqueza de las naciones (construida a partir del interés) fuera una parte de un orden más general y no meramente del orden humano: esperamos que el mundo "feo» en el que vivimos sea un mundo que Dios ama; y con este amor la fealdad se vuelve menos fea. Es la esperanza, por decirlo de otro modo, en que el mundo humano contingente, frágil e histórico, realmente pueda haber acertado en lo que desde su pequeñez ha construido. El orden conseguido por el hábil político, el hecho de que somos capaces de con elementos muy rastreros organizar una nación próspera y rica donde da gusto vivir, es algo que el hombre que tiene fe toma con la confianza de que sus pasos van coincidiendo con los pasos que Dios andaría o gustaría de andar. Para darlos no es preciso ser un creyente, no es necesario tener una religión determinada, sino simplemente ser capaz de percibir el obvio sentimiento religioso que anida en cualquier hombre civilizado. Esto es prácticamente un imperativo moral para Mandeville; hay Providencia y de tal modo ni siquiera el mal es un mal: "El conocimiento que Dios posee es perfecto desde la eternidad. La sabiduría infinita no está sometida a errores o faltas, por consiguiente, todas sus obras son 
universalmente buenas y todas las cosas están hechas como se propuso hacerlas» (Free Thouths, 534). Quizá aquí Mandeville lo tenía fácil pues aun proponiendo una doctrina que no necesita en ningún punto de la fe, lo hace desde la comodidad de un hombre de fe. Esto se ve muy claro en los dos últimos diálogos de la segunda parte de La fábula donde la voz de Mandeville, Cleómenes, se enfrenta a quien había sido hasta ese momento el hombre que sostenía la voz equivocada que creía en la virtud, Horacio. Este, se ve sorprendido con la afirmación de que no toda religión ha de ser falsa y que la religión cristiana tiene todos los visos de ser verdadera y cuando espeta a Cleómenes-Mandeville que eso no se sostiene con lo que ha estado defendiendo hasta ese momento, la respuesta es bien poco convincente: es cierto que no se sostiene, pero de alguna manera quizá merezca la pena dar vueltas al intento de sostenerlo. Mandeville necesita un amigo que encuentra en Dios. ${ }^{21}$

Al final hay una cierta interconexión entre la religión y la fe; paradójicamente es una conexión que invierte los términos con los que se inició el camino de la fe en el mundo humano: la religión construye nuestro mundo, la fe nos presta la esperanza de que tal mundo es el más adecuado, pero no porque a nosotros así nos parezca. Estoy convencido de que en una sociedad comercial compleja esta es una esperanza obligada para todo hombre. Una esperanza que no es privada sino social pues nos da fuerza para vivir con otros en un mundo hecho en una escala humana, sin fe. Dios, al final, es un amigo y la fe, no la religión, nos da ánimos para afrontar los recodos del camino difícil de la vida. ${ }^{22}$

\section{BiBLIOGRAFÍA}

Critchley, S. 2012. The Faith of the Faithless: Experiments in Political Theology. Nueva York: Verso Books.

Hundert, E. J. 2005. The Enlightenment's Fable. Bernard Mandeville and the Discovery of Society. Cambridge: Cambridge University Press.

Jack, M. 1975. «Religion and Ethics in Mandeville», en I. Primer (ed.), Mandeville Studies: 35 y ss. La Haya: Martinus Nijhoff.

Jack, M. 1987. The Social and Political Thought of Bernard Mandeville. Londres: Garland.

James, E. D. 1975. "Mandeville and Bayle», en I. Primer (ed.), Mandevile Studies. La Haya: Martinus Nijhoff.

Monro, H. 1975. The Ambivalence of Bernard Mandeville. Oxford: Clarendon Press.

Nokes, D. 1987. Raillery and Rage. A Study of Eighteenth-Century Satire. Brighton: The Harvester Press.

Peltonen, M. 2003. The duel in Early Modern England. Civility, Politness and Honour. Cambridge: Cambridge University Press.

Scribano, M. E. 1980. Natura unama e societá competitiva. Studio su Mandeville. Milán: Feltrinelli.

Simonazzi, M. 2008. Le favole della filosofia. Saggio su Bernard Mandeville. Milan: Franco Angeli.

Simonazzi, M. 2015. "Atheism, Religion, and Society in Mandeville's Thought», en E. Balsemâo y J. Braga (eds.), Bernard Mandeville's Tropology of Paradoxes. Morals, Politics, Economics and Therapy. Heildeberg: Springer.

Tolonen, M. 2013. Mandeville and Hume: Anatomists of Civil Society. Oxford: Voltaire Foundation.

Wilde, N. 1898. "Mandeville's Place in English Thought». Mind 7 (26): 219-232.

21 En el Dios cristiano por supuesto: «Cleómenes: [...] Adán fue enteramente la obra de Dios; una producción preternatural. Su lenguaje y su conocimiento, su bondad y su inocencia eran tan milagrosos como cualquier otra parte de su ser. Horacio: Realmente, Cleómenes, esto es insufrible. Mientras estamos hablando de filosofía introduces clandestinamente los milagros. ¿Por qué no puedo yo hacer lo mismo [...]? Cleómenes: Es más probable que un milagro haya producido en una ocasión determinada un hombre y una mujer de los cuales ha derivado por vía natural el resto de la humanidad, que el que mediante una serie continua de milagros varias generaciones hayan sido hechas para vivir y obrar de modo contrario a su naturaleza» (The Fable: II, 309 [576]).

22 Por ello los ateos, los sin esperanza, son infelices o libertinos que se autoengañan: "Los ateos son especulativos o prácticos; los ateos especulativos son aquella gente infeliz que siendo demasiado afectos del conocimiento o del razonamiento son primero engañados con el escepticismo hasta que incapaces de librarse de los laberintos de la filosofía son al final conducidos a no creer en ninguna cosa que no puedan comprender [...] Los ateos prácticos habitualmente son libertinos que en primer lugar son culpables de todo tipo de vicio y profanaciones y posteriormente, no atreviéndose a reflexionar sobre la enormidad de sus pecados o de los castigos que merecen de la venganza divina, se agarran a los argumentos ateos para protegerse de sus propios miedos» (Free Thoughts: 4-5). 